\title{
Measuring system for amperometric Chemical SENSORS USING THE THREE-ELECTRODE TECHNIQUE FOR FIELD APPLICATION
}

\author{
P.R.Hernández ', C.A.Galán ², A.Morales ${ }^{3} \&$ S. Alegret 4. \\ ${ }^{1}$ Centro de Investigación y de Estudios Avanzados del IPN, Ingeniería Eléctrica. \\ 2 Universidad Autónoma de Hidalgo, Química Analítica. \\ ${ }^{3}$ Universidad Nacional Autónoma de México, FES Cuatitlán \\ ${ }^{4}$ Universitat Autònoma de Barcelona, Química Analítica \\ phernand@mail.cinvestav.mx
}

Received: September $13^{\text {th }} 2000$ and accepted June $21^{\text {th }} 2002$.

\begin{abstract}
A portable and low cost measuring system for amperometric chemical sensors using the three-electrode technique was developed. This technique allows chemical sensors to work with currents higher than ten microamperes. The system was based on a potentiostat operation, completed with an I-V converter and signal conditioning circuits. The instrument was evaluated comparing calibration curves of hydrogen peroxide, proving several amperometric chemical sensors and biosensors, to those obtained from a very expensive commercial equipment. Good linearity and sensibility as well as low noise measurements were obtained. Moreover, because the reduced size and low cost, the instrument allows to be used directly in field applications.
\end{abstract}

\section{RESUMEN}

Se presenta el desarrollo de un sistema de medición portátil y de bajo costo para sensores químicos amperométricos, utilizando la técnica de tres electrodos. Esta técnica permite a los sensores químicos trabajar con corrientes arriba de diez microamperes. El sistema se evaluó comparando curvas de calibración de peróxido de hidrógeno, probando varios sensores químicos amperométricos y biosensores, con aquellas obtenidas de un equipo comercial de alto costo. Se obtuvo una buena linearidad y sensibilidad, así como bajo ruido en las mediciones. Además, debido al tamaño reducido y a su bajo costo, el instrumento permite ser utilizado directamente en aplicaciones en el campo.

KEYWORDS: Electrochemical sensors, amperometric sensors, amperometric unit, ampermeter.

\section{INTRODUCTION}

The group of electrochemical sensors is the widest and oldest of chemical sensors. Some have achieved commercialization but others are still in development [1].

Amperometric sensors use transference processes of ionic to electronic charges between electroactive species and an electrode. An electrical current is settled through the device immersed in a solution and directly related to the species concentration. A two-electrode arrangement (working and reference electrodes) can be used when low currents are needed. However, when currents higher than ten microamperes are employed, reference potential losses, become important and subjected to characteristics of the solution. Consequently, some changes are generated in the reference electrode that modify the cell 
stability. In this case, an auxiliary electrode is added to the cell avoiding current pass by the reference electrode.

Development of the amperometric sensors is being focused to reduce size and cost, to be simple and easily reproduced. With these features, sensors could be commercialized and could open new application fields. Some efforts have been done in this sense [4], taking advantage of screen-printing technique, which in several easy steps can form the structure of the sensor.

Accordingly, instrumentation must be designed to fulfill similar requirements to complete a very useful but simple, reliable and portable measuring amperometric system.

Some equipment has been developed, one is specific for a particular sensor and has been focused to clinical applications. The other, sophisticated but expensive and non portable has been designed for researching in laboratory. None of them represent a good option for field applications because of their cost and some limitations in their operating characteristics.

In the present work, a portable instrument for amperometric sensor devices with a wide range of operating currents, but maintaining a high quality in the measurements is described.

\section{METHOD AND MATERIALS}

\subsection{Electrodes}

Thick-film electrodes for hydrogen peroxide measurement were used [4]. Accordingly, they were based on a graphite-epoxy composite layer deposited over a cooper track and supported by a glass-fiber substrate. The area of the sensor, not submitted to the dissolution, was protected by an isolating polymer deposition. The amperometric measurement system was completed by the use of an $\mathrm{Ag} / \mathrm{AgCl}$ reference electrode (Orion 92-02-00) with $\mathrm{KCl} 0.1 \mathrm{M}$ in the outer chamber and a platinum (Ingold) auxiliary electrode.

\subsection{Design}

Technical results for measuring currents in electrochemical cells were considered from the literature [3]. It is suggested a two-electrode arrangement for currents lower than ten microamperes. But if reliability is looking for currents upper that value, a three-electrode array is recommended. Figure 1 shows a block diagram of the instrument.

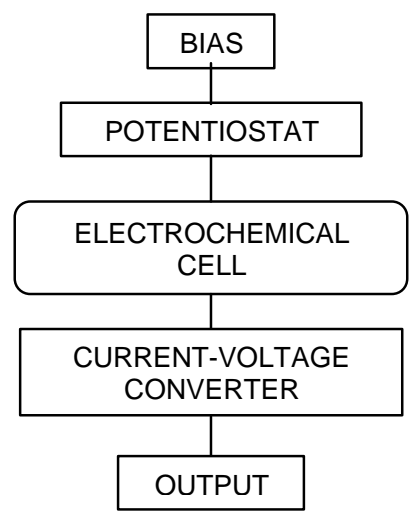

Figure 1. Block diagram of the measuring system for amperometric sensors 
Potenciostat is a circuit for maintaining invariable the voltage between reference and working electrodes. The circuit compensates possible voltage losses due to the chemical solution and also permits a very low current circulation by the reference electrode.

The I-V converter, outputs a voltage proportional to the working electrode current and the output circuit adequates its current-voltage values to those corresponding to chemical concentration; two amplification factors were required.

An adjustable circuit for cell polarization in the range $0-2.5 \mathrm{~V}$ and another for compensating purposes when expanded scale is needed, were also included. Once a characterized electrode is used, both circuits can be mainly reduced.

\subsubsection{Potentiostat}

The basic circuit of a potentiostat is represented by a feedback circuit, which compensates voltage drops generated between the working electrode and the reference one. The circuit is shown in figure 2 . The integrated circuit (IC) U1, operational amplifier, outputs a potential equal to potential for polarizing the working electrode plus losses originated in solution. The IC U2, is the sensor to feedback an error voltage through resistor R2. Consider the circuit shown in figure 2, Rc and Rw are hypothetical resistors of chargetransfer resistance of disolution zones between auxiliary and reference electrodes and between reference and working electrodes respectively.

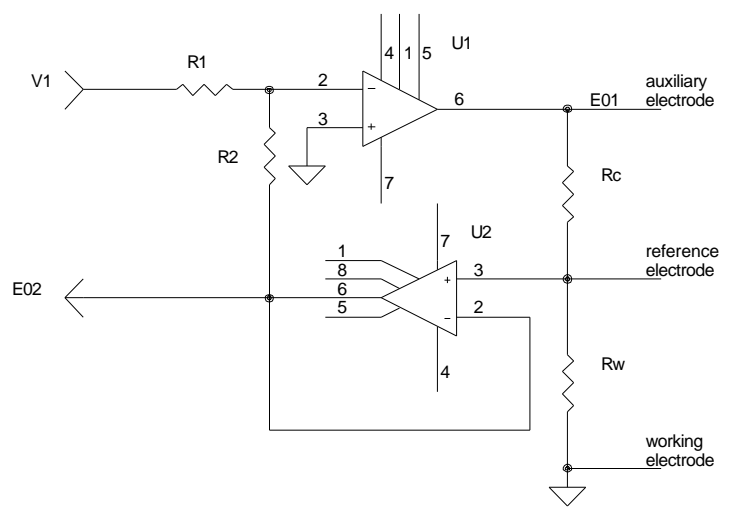

Figure 2. Schematic diagram of the potentiostat circuit.

For $\mathrm{U} 1$, with $\mathrm{e}_{1}=0$, and this case $\mathrm{R} 1$ and $\mathrm{R} 2$ equal,

$$
e_{2}=\frac{1}{2}\left(V_{1}-E_{02}\right)+E_{02} \text {. }
$$

The circuit U2, as voltage follower from the hypothetical network of Rc and Rw, works according to the equation

$$
e_{2}=\frac{R_{w}}{\left(R_{w}+R_{c}\right)}
$$

Combining (1) and (2) and making some practical considerations like a very large open-loop amplification factor of the operational amplifier and the working and reference electrodes close together in solution, the condition $\mathrm{Rw}<<<<\mathrm{Rc}$ can be accepted. Then, we have the expression

$$
E_{02}=-V_{1}
$$


which means the reference electrode potential can be set ignoring $\mathrm{Rw}$ and Rc effects. This condition and the virtual ground in the I-V converter circuit, establish the potential difference between the reference and working electrodes, once preset, to be constant.

The IC U1 is an operational amplifier of type TL081 with FET input, low noise and a high common mode rejection expratio(CMRR), cheap and accessible in the market.

The circuit U2, type CA3140, is a device with very high input impedance $\left(10^{12} \Omega\right)$, low noise, high CMRR and also cheap. A filtering network was added to the bias lines of this circuit, capacitors for low frequencies and chokes for high ones. A potentiometer P8 was connected to provide offset adjustment.

The I-V configuration uses the condition of virtual ground on the input $e_{2}$, which acts as a sum point. This is shown in figure 3 and can be expressed

$$
I_{c}=-I_{r}
$$

where Ic is the input current of this circuit. It also corresponds to the current passing by auxiliary and working electrodes. The current Ir passes by the feedback resistor $\mathrm{Rr}$.

The output voltage $\mathrm{Vo}$ of I-V converter is given by

$$
V_{0}=-I_{c} R_{r}
$$

or

$$
V_{o}=I_{r} R_{r}
$$

The output voltage of I-V converter will be proportional to the current passing by the electrochemical cell from the auxiliary to working electrodes. The circuit was designed for currents up $100 \mu \mathrm{A}$ without saturation.

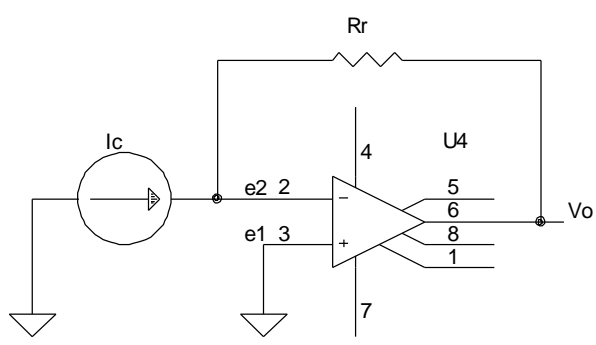

Figure 3. Circuit for current - voltage conversion

\subsubsection{Output circuit}

Circuit is based on an operational amplifier type TL081 as an inverter amplifier configuration with factors from 1 to 10 . An intercept compensation may be done applying an adjustable voltage through R7. This is useful when little changes are to be measured and relatively high dc potentials are present. Data is presented using a 31/2 liquid crystal display voltmeter and an analog output is available for a plotter or an acquisition PC-based system. Schematic diagram of the complete instrument is shown in figure 4.

\subsubsection{Electrochemical Set up}

The enzymatic reaction developed in the measuring process is represented as follows 


$$
\beta \text {-D-Glucose }+\mathrm{O}_{2} \stackrel{\begin{array}{c}
\text { Oxidase } \\
\text { glucose }
\end{array}}{\longrightarrow} \text { Gluconic acid }+\mathrm{H}_{2} \mathrm{O}_{2}
$$

The hydrogen peroxide $\left(\mathrm{H}_{2} \mathrm{O}_{2}\right)$, formed from the reaction between $\beta$-D-glucose and oxidase glucose enzyme, is oxidized when $1200 \mathrm{mV}$ potential is applied to the working electrode. Concentration of hydrogen peroxide is directly proportional to the $\beta$-D-glucose concentration. Experimentally, $20 \mathrm{ml}$ base electrolyte solution ( $0.1 \mathrm{M}$ phosphate solution, $\mathrm{pH}=7.0$ ) was used hoping a stable basal. Subsequently, samples of standard solution $\beta$-D-glucose were added and resultant currents were recorded.

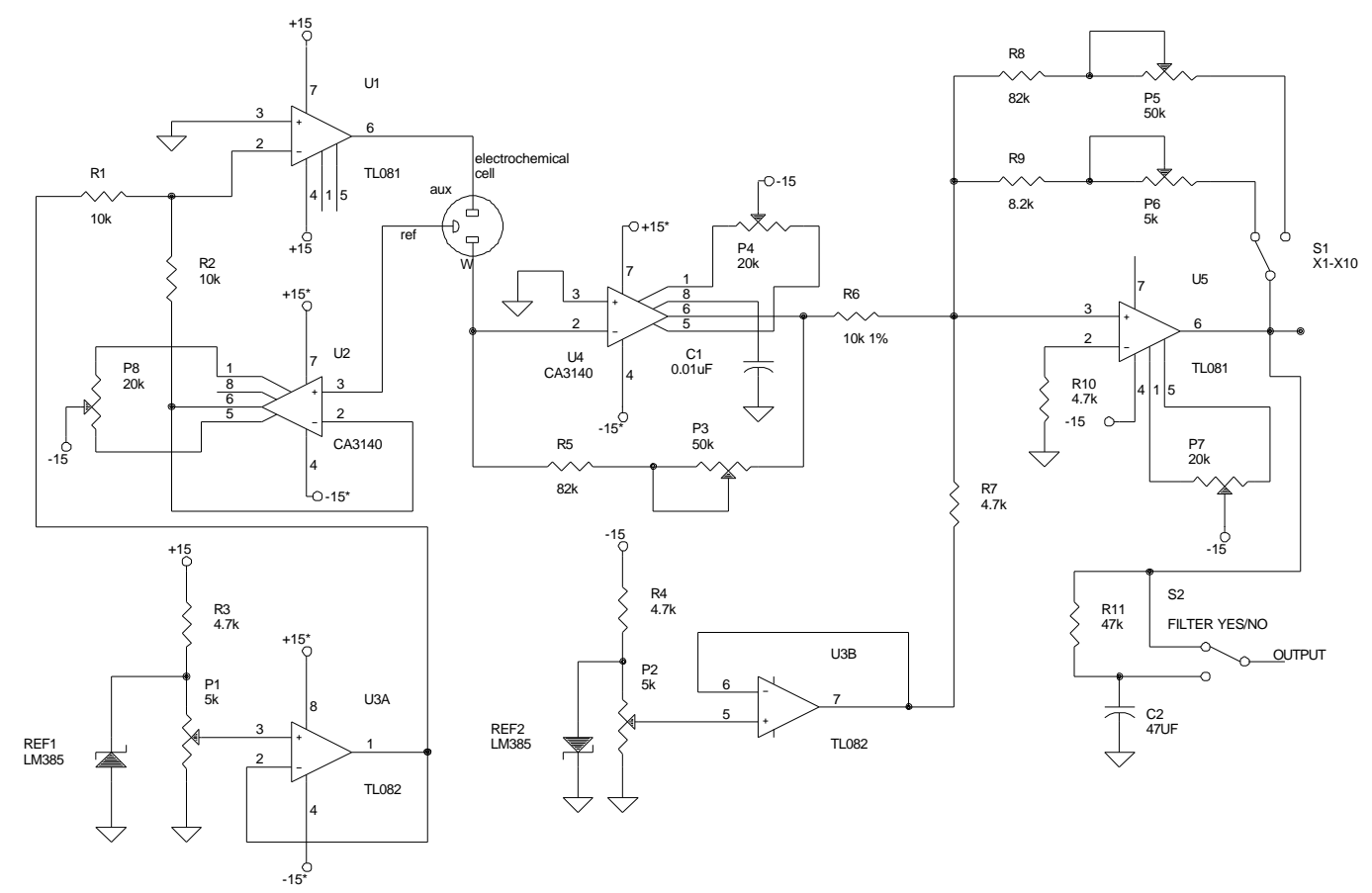

Figure 4. Schematic diagram of the three-electrode instrument for amperometric measurements.

Table I. Calibration parameters with hydrogen peroxide for flat graphite-epoxy amperometric sensors in three-electrode configuration, $1200 \mathrm{mV}$ potential applied and a $0.1 \mathrm{M}$ phosphate, $0.1 \mathrm{M} \mathrm{KCl}, \mathrm{pH}=7$ working solution.

\begin{tabular}{|c|c|c|c|}
\hline \multicolumn{4}{|c|}{ Developed equipment } \\
\hline Calibration & 1 & 2 & 3 \\
\hline $\mathrm{R}^{2}$ & 0.9831 & 0.9982 & 0.9984 \\
\hline $\mathrm{b}(\mu \mathrm{A})$ & -0.23858 & -0.00604 & -0.000142 \\
\hline $\mathrm{m}(\mu \mathrm{A} / \mathrm{mM})$ & 41.89364 & 36.95652 & 29.86690 \\
\hline \multicolumn{4}{|c|}{ Commercial unit } \\
\hline $\mathrm{R}^{2}$ & 0.9995 & 0.9960 & 0.9992 \\
\hline $\mathrm{b}(\mu \mathrm{A})$ & 0.020802 & -0.07923 & -0.0205 \\
\hline $\mathrm{m}(\mu \mathrm{A} / \mathrm{mM})$ & 37.81473 & 30.50483 & 27.06437 \\
\hline
\end{tabular}




\section{RESULTS}

Three amperometric and consecutive calibrations of hydrogen peroxide, with the developed instrument and a commercial unit (Metrohm 641 VA-Detector), were obtained and compared using the same transducer. Results from both measurements units are shown in table I. It can be noted that sensitivity, the slope of the calibration curve, decreases with the number of calibration in both the developed and commercial units. This kind of responses are normal considering that screen-printing planar electrodes are intended for being used only once. Additionally, sensitivity resulted higher in the test for the developed unit. In contrast, linearity correlation factor $r^{2}$ was lower meaning a higher dispersion of experimental data.

\section{CONCLUSION}

Even though some differences were obtained when the developed instrument was technically compared with a commercial one, technical and physical characteristics of the developed unit, make it a good option, complemented with disposable electrodes, for amperometric measurements directly made in field.

\section{REFERENCES}

[1] Janata J., Principles of chemical sensors, Plenum Press, New York, 1989.

[2] Bostwick K.G., Bougher J., Kissinger P.T., Battery-powered potentiostats for LCEC and amperometric biosensors, Current separations, 13:1 (1994) 28-29.

[3] Bard A.J. and Faulkner L.R., Electrochemical methods, Fundamentals and applications, John Wiley \& Sons, 1980, USA.

[4] Galán Vidal C. A., Desarrollo de sensores químicos por tecnología thick-film, Universitat Autònoma de Barcelona, Departamento de Química, Bellaterra España, 1995. 


\section{Authors biography:}

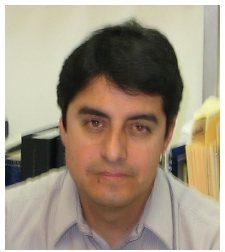

\section{Pablo Rogelio Hernández Rodríguez}

Was born in Mexico on June 26th, 1953. He received a BSc degree in Electronics in 1978 and a MSc in Bioelectronics in 1979 from the Instituto Politécnico Nacional (National Polytechnic Institute). He was awarded a Ph.D. from the CINVESTAV IPN, Mexico, in 1995. He is a lecturer-researcher at the CINVESTAV IPN in México City on the design of chemical sensors and the instrumentation for electrochemical measurements.

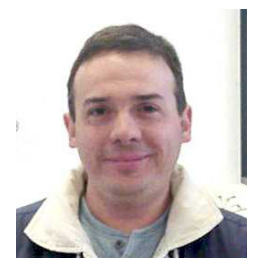

Carlos Andrés Galán Vidal

Was born in Mexico on November $4^{\text {th }}$, 1963. He received a BSc in chemistry from the Universidad Nacional Autónoma de México (National Autonomous University of Mexico) and was awarded the PhD in chemistry from the Universidad Autónoma de Barcelona (Autonomous University of Barcelona) in 1996. He is a Senior Lecturer Researcher in the Universidad Autónoma del Estado de Hidalgo (Autonomous University of Hidalgo State, México), and he is currently working on the study and development of chemical sensors and biosensors.

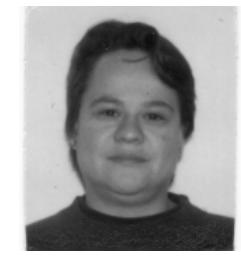

Adriana Morales Pérez

Received a BSc in chemistry, a MSc in physical chemistry, both from the Universidad Nacional Autónoma de México (National Autonomous University of Mexico), and was awarded the $\mathrm{PhD}$ in chemistry from the Universidad Autónoma de Barcelona (Autonomous University of Barcelona) in 1995. She is a Senior Lecturer Researcher in the Universidad Nacional Autónoma de México and she is currently working on the study and development of chemical sensors and biosensors.

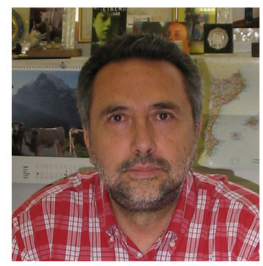

Salvador Alegret Sanromán

Was born in Barcelona Spain on January 26th 1947. He received a BSc in chemical engineering in 1973, and was pawarded a PhD from the Universitat Autònoma de Barcelona in 1978. He is a Senior Lecturer Researcher in the Universitat Autònoma de Barcelona on chemical analysis, electroanalysis, chemical sensors, biosensors, biomimetic sensors and analytical bioinstrumentation for monitoring and measurement purposes. 